\title{
Five years' experience with a primary care electronic patient record in a community sexual and reproductive health service
}

\author{
Lesley Bacon, ${ }^{1}$ Dale Coley, ${ }^{2}$ Eleanor Draeger, ${ }^{3}$ Jacqueline Evans ${ }^{4}$
}

${ }^{1}$ Consultant in Sexual and Reproductive Health, Lewisham and Greenwich NHS Trust, London, UK

${ }^{2}$ IT Analyst, Sexual and Reproductive Health, Lewisham and Greenwich NHS Trust, London, UK

${ }^{3}$ Genitourinary Medicine Consultant, Lewisham and Greenwich NHS Trust, London, UK

${ }^{4}$ Associate Specialist in Sexual and Reproductive Health, Lewisham and Greenwich NHS Trust, London, UK

\section{Correspondence to} Dr Lesley Bacon, Lewisham and Greenwich NHS Trust Sexual and Reproductive Health, Waldron Health Centre, Amersham Vale, London SE14 6LD, UK; lesleyebacon1234@aol.com

Received 27 April 2014 Revised 29 July 2014 Accepted 23 October 2014 Published Online First 18 November 2014

\section{CrossMark}

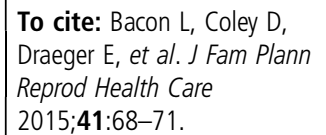

\section{WHY WAS CHANGE NEEDED?}

Lewisham Sexual and Reproductive Health (SRH) service is one of the largest in the UK with approximately 60000 attendances a year. It works from four centres spread across a deprived innercity area of London. In 2008 we changed to an electronic patient record for the following reasons.

- We ran out of space. In 2007 it became obvious that the approximately 80000 sets of paper notes that were kept in the four centres were presenting an insuperable storage problem. We also had the occasional misfiled set of notes, which presented a clinical governance risk. ${ }^{12}$

- We needed to be able to produce data for audit and mandatory reports more flexibly than was possible with paper records. Our previous system of recording data (on an optical reader sheet that was scanned and then analysed) was far too time consuming and could not be changed as requirements altered.

- We needed to be able to see all our records in all four of our centres. Many of our patients use our centres interchangeably and this led to frustrations and inefficiencies, not least because of the time taken for notes to be transported between clinics. Our senior nurses now lead more clinic sessions; telephone advice from senior doctors is safer if the doctor can see the complete record from a distance.

- We needed to employ staff more efficiently. One important consideration for us was that the administrative staff could be freed up from mundane chores such as preparing blank sets of notes, and be able to devote more time to front-of-house work and to managing our increasing numbers of pathology results (e.g. those from the chlamydia screening programme); 38 hours of results management per week were gained in this way.

\section{WHAT CHANGES DID WE MAKE?}

We investigated several information technology (IT) systems that had been developed for hospital-based genitourinary medicine (GUM) services, but none of those available at that time were easy to use for detailed contraception consultations or coding, and they collected more information on infection work than we needed.

As the bulk of our work at the time was in SRH we prioritised having a system with the ability to deal with contraception. However, we needed a system that could gradually incorporate infection work (because we had already started moving towards an integrated model encompassing both sexually transmitted infections and contraception). The system that seemed to offer most flexibility in 2007/2008 was EMIS $^{\circledR}$ PCS (Egton Medical Information Systems Limited, Leeds, UK). ${ }^{3}$

EMIS is an electronic patient record originally designed for use in UK general practitioner (GP) surgeries. It is now used in over half of all UK GP practices, and includes the ability to use clinical codes which can be searched, thus transforming the audit process. Since it is so widely used it has excellent support systems. We used EMIS PCS, but this will not be supported from the end of March 2015; the replacement is EMIS ${ }^{\circledR}$ Web.

\section{HOW DID WE SET THE SYSTEM UP?}

In 2008 we still had some staff with little basic computer literacy, so support and 
mentoring was arranged for these individuals in advance. A project manager was employed to help implement the new system, but we relied heavily on one of the doctors who was familiar with EMIS and IT-literate enough to write many of our first templates. We now have a 0.8 whole-time equivalent data analyst who maintains our local system and processes clinic data.

All members of staff had dedicated, off-site training from the Trust IT department (between 0.5 and 2 days depending on their role). An in-house handbook was written, and copies made available to all staff.

The changeover week was carefully planned, with one centre changing each day and IT assistance available in each clinic to troubleshoot. Local GPs were warned that we might slow down for a while, as we had to summarise the existing patient notes onto the new system. This was very quick for most patients, but any lengthy or complex notes were passed to senior doctors to summarise.

\section{WHAT DOES THE SYSTEM LOOK LIKE?}

The basic programme starts with an appointment sheet for each day (Figure 1), which can be customised and can also be used for walk-in sessions. It indicates clearly which patients have been booked in, seen or left. By using the facility to include 'branch surgeries' we are able to have one electronic record across all of our four centres, and also our outreach clinics and sessions for HIV patients.

A consultation screen is provided, on which records can be entered in free text or by using a series of templates (screens designed to enable routine consultations to be entered using tick boxes, which act as an aide-mémoire as well as decreasing the amount of typing needed) (Figure 2). The consultation can also be used to enter national Read codes, which enables audit to be speeded up and statutory returns to be done by searching.

Prescriptions are written on the computer using drugs available in the current British National Formulary. We set up our own formulary, so that prescriptions fill in quickly and automatically (e.g. 3 months of pills, which can be quickly modified to 6 , 9 or 12 months), even though we do not print the prescription but dispense in the clinic.

The vast majority of our test results are delivered electronically, and can be entered into the patient record and actioned from any site by our team of results nurses.

EMIS has a link to Microsoft Word, so that letters can be written within the programme and then emailed and/or printed as appropriate. Incoming letters, patient registration forms and other documents can be scanned and stored on the system, and images such as ultrasound scans can be uploaded. E-mails to and from patients or to other clinicians can be copied and pasted into the patient's record.

We still have a backup paper system to use if the IT fails, but this has been needed rarely, about 10 times in 5 years. The Trust IT service ensures that the system (which is stored on a central server in University Hospital Lewisham) is backed up daily.

\section{WHAT HAVE BEEN THE OUTCOMES OF THIS CHANGE FOR US? \\ Clinic management}

In just over 5 years we now have 96500 registrations on our system. Approximately 700 (0.7\%) are duplicates, and we know that some people have registered

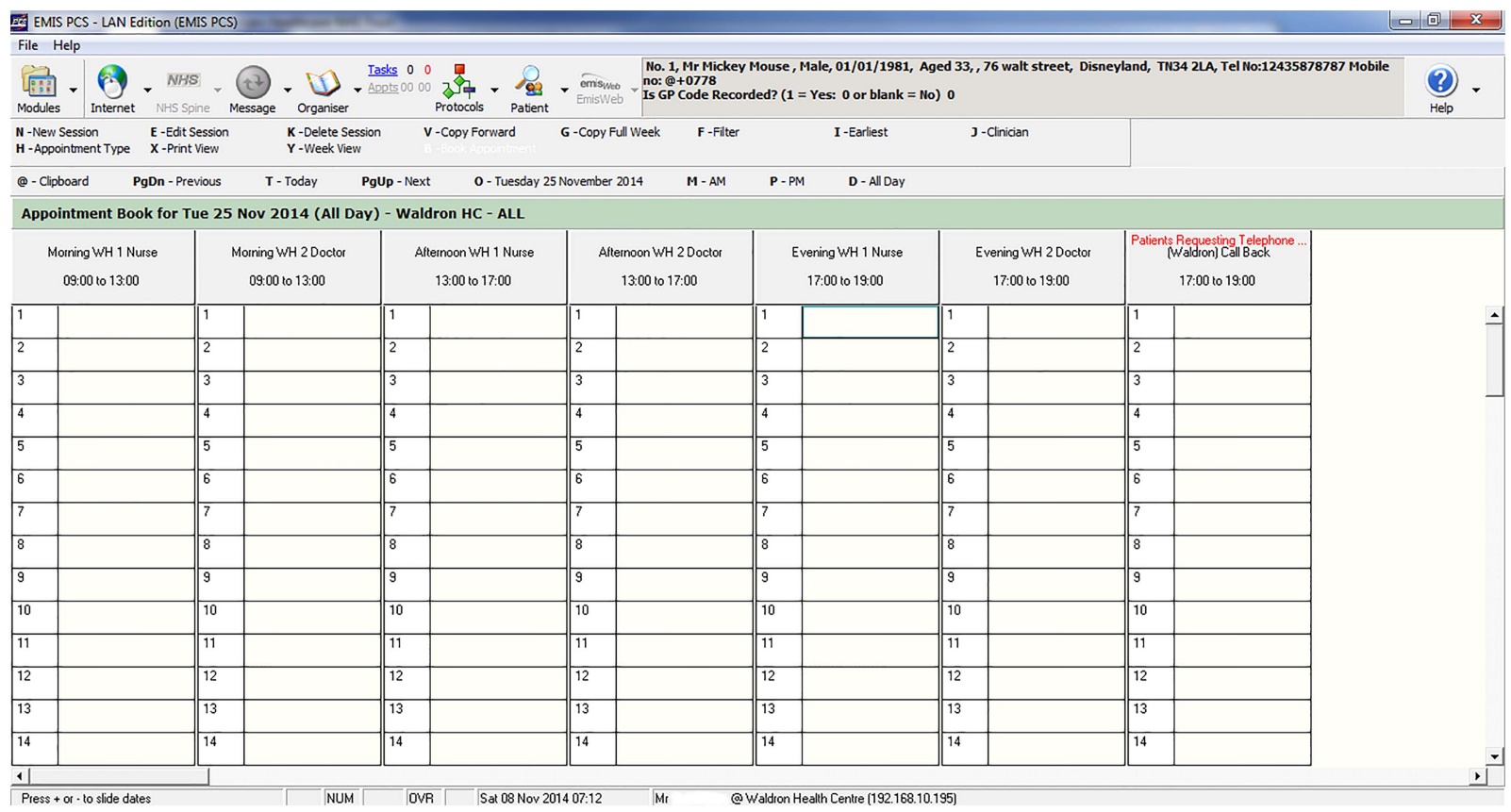

Figure 1 Example of a blank daily appointment sheet on EMIS ${ }^{\circledR}$. 


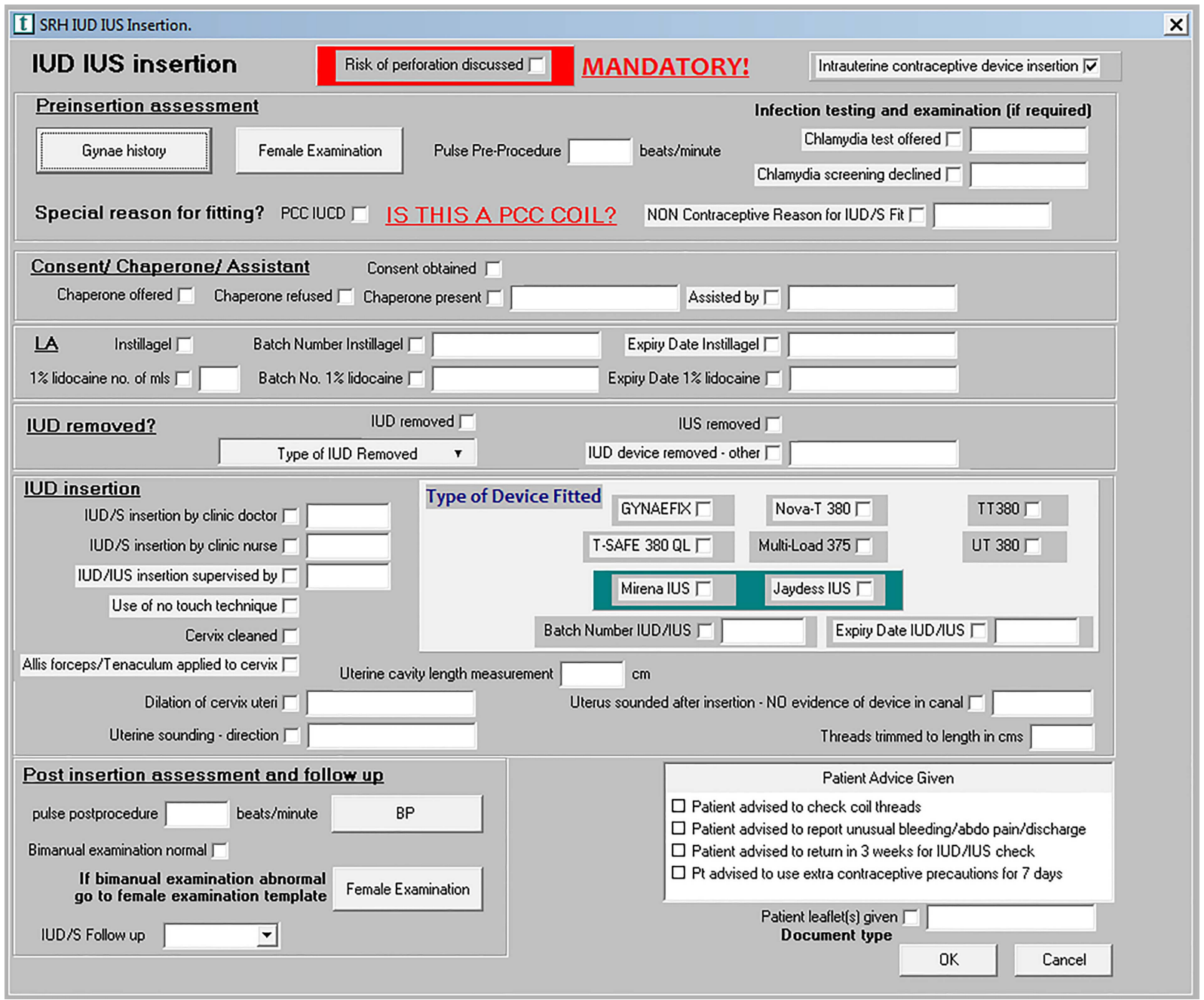

Figure 2 Template for intrauterine device insertion available on the EMIS ${ }^{\circledR}$ consultation screen.

more than once under different names. We have on many occasions been able to spot this on EMIS, as it is possible to search by name, address, postcode, date of birth or mobile phone number. Most of our paper notes are now in secure storage, freeing up clinic space.

Clinical audit is an essential part of clinical governance. Using paper notes, carrying out an audit could be very time consuming and ran the risk of some sets of notes being 'lost' and others being illegible. With an electronic record it is possible to search the whole database in minutes and look at all of the retrieved notes; records do not have to be removed from the clinic at all. A recent check revealed that obtaining a list of the 2465 women who had been prescribed Levest $^{\circledR}$ over the last 12 months, and sending it to a spreadsheet, took 3 minutes.

The audit function is also invaluable for revalidation purposes. Instead of keeping an individual log of implant insertions/removals or intrauterine device/ system insertions the clinician can search under their name and the relevant procedure and pull up all the related notes as and when they need them.

\section{Results management}

We have added tQuest ${ }^{\mathrm{TM}}$ (Indigo 4 Systems Limited, Sheffield, UK) ${ }^{4}$ to our system. This is a web application used by a number of organisations to request tests for pathology and radiology within the primary care environment. Request forms are printed in the clinic room, and this also notifies the laboratory that the sample is expected. The results are then returned electronically.

As we move towards full integration of SRH and GUM the number of tests we are sending has risen sharply. We are therefore now investigating different ways to deliver patients' results automatically. We are also using a texting service linked to EMIS to remind patients of appointments, and to enable them to cancel appointments that they do not want; this has proved to be very helpful in reducing our 'Did Not Attend' rate for appointment sessions (from $27.8 \%$ in the 4 months before texting began to $21.1 \%$ in the 4 months after texting commenced).

\section{WERE THE STAFF HAPPY WITH EMIS?}

We recently carried out a user satisfaction survey of EMIS in our clinics. Twenty-seven members of staff (7 
doctors, 10 nurses and 10 administrative staff) responded. To the question "How satisfied are you with the EMIS system?" $78 \%$ said they were 'satisfied' or 'very satisfied'. The question "Would you recommend EMIS to another clinic?" was answered as 'recommend' or 'strongly recommend' by $78 \%$ of respondents.

\section{ADVICE TO OTHERS CONSIDERING CHANGE}

Examine all software options carefully; do not let yourself be coerced into using a system that is not right for you. Make sure that the system works quickly and smoothly, and work with your IT department to make sure that the hardware and backup are adequate. The development of sexual health IT systems is fast-moving; make sure that your provider is likely to be able to provide support in the medium term.

Do not underestimate the amount of time needed for preparation: from the first discussions to 'going live' took us about 2 years.

Lack of familiarity with computers was an issue for some staff members. Over the last 5 years this has become an increasingly rare problem but some staff may still need extra help and may be embarrassed to admit it.

The computer can become a barrier to the consultation $^{5}{ }^{6}$ and staff should remember that in a sensitive or difficult situation they may need to revert to making paper notes and typing these up afterwards. This is especially true for those staff members who cannot touch-type as eye contact with patients can be lost.

It is also important to remember that the patient may be reading the notes as they are written or on a return visit to the clinic; consequently sensitive information has to be recorded appropriately.

\section{Competing interests None.}

Provenance and peer review Not commissioned; externally peer reviewed.

\section{REFERENCES}

1 Fairley C, Vodstrcil L, Huffam S, et al. Evaluation of Electronic Medical Record (EMR) at a large urban primary care sexual health centre. PLOS ONE 2013;8:e60636.

2 Bigrigg A. Are computers of any use in a family planning clinic? Br J Fam Plann 2000;26:100-103.

3 http://www.emis-online.com/emis-pcs [accessed 17 April 2014].

4 http://www.indigo4.com/products-and-services/tquest-review [accessed 27 April 2014].

5 Dowll A, Stubbe M, Scott-Dowell K, et al. Talking with the alien: interaction with computers in the GP consultation. Aust J Prim Health 2013;19:275-282.

6 Pearce C, Dwan K, Arnold M, et al. Doctor, patient and computer - a framework for the new consultation. Int J Med Inform 2009; 78:32-38.

\section{READERS' CONTRIBUTIONS INVITED ON 'A BETTER WAY OF WORKING'}

The Journal publishes occasional 'A Better Way of Working' articles, the purpose of which is to disseminate service delivery suggestions likely to be of interest and relevance to the Journal's readership. Readers are invited to submit suggestions based on their own personal experience for consideration by the Journal Editor. Contributions normally should not exceed 1000 words and should be written in a standardised format responding to the following four questions (or similar): Why was change needed? How did you go about implementing change? What advice would you give to others who might be considering a similar course of action? How did you show that the change had occurred? All contributions should be submitted via the Journal's online submission system at http://mc.manuscriptcentral.com/jfprhc. 